ORIGINAL RESEARCH

\title{
Admission academic metrics and later success in an accelerated master's entry program
}

\author{
Elizabeth Ann Doyle *, Deborah Fahs, Linda Honan \\ Yale School of Nursing, Yale University, USA
}

Received: July 31, 2019

Accepted: September 8, 2019

Online Published: September 23, 2019

DOI: $10.5430 /$ jnep.v10n1p33

URL: https://doi.org/10.5430/jnep.v10n1p33

\begin{abstract}
Background: Accelerated master's entry programs for non-nurse college graduates leading to advanced practice, which are both rigorous and fast-paced, utilize academic metrics to evaluate prospective candidates, including GRE scores and GPA levels. Because this program saw an increased rate of failure from the program (with medical-surgical nursing being associated with $>$ 93\% of failures), the aim of this study was to examine if either of these metrics were associated with later success in the program. Methods: A retrospective, descriptive study analyzed admission metrics and first year academic performance to determine if any criteria were associated with academic success. Data collected included age, gender, race, ethnicity, GPA, GREs and scores on the seven required courses in the first 25 weeks. $T$-tests, correlations, ANOVAs and multiple regression were used to determine if any significant relationships existed.

Results: Admission data from 333 students revealed no differences in the mean GPA related to academic success. Students who failed out of the program $(n=15)$ had significantly lower GRE quantitative, verbal, and writing scores. Additionally, quantitative and verbal scores correlated with exam scores on many didactic courses, and explained $25.4 \%$ of the variance in the first medical-surgical exam scores $(p<.001)$, with GRE quantitative scores having the most effect.

Conclusions: This study demonstrated verbal and quantitative scores were the only predictor of academic success suggesting admission offices might consider whether this current trend of omitting GREs is meeting the needs of students, faculty, universities and the public at large.
\end{abstract}

Key Words: GRE Scores, Nursing graduate programs, Accelerated Nursing Master's Entry Programs, Academic success

\section{INTRODUCTION}

Accelerated Master's Entry Nursing Programs are for nonnurse college graduates who are considering a career in nursing. In the United States there are currently 64 accelerated Master's entry programs for non-nurse college graduates but of these, only 21 colleges or universities offer Advanced Practice Registered Nurse (APRN) programs, which lead to advanced practice including preparation as a Nurse Practitioner (NP), Clinical Nurse Specialist (CNS), Certified NurseMidwives (CNM) and Certified Registered Nurse Anesthetist
(CRNA). ${ }^{[1,2]}$ These programs are rigorous, and fast paced, typically requiring over 30 credits in 11-12 months, and success on the National Council Licensure Examination for Registered Nurses (NCLEX-RN) before advancing to their respective two year specialty program. To determine whether potential candidates are suited for such a rigorous program, various academic metrics (along with other admission data) are collected from the applicant and are reviewed by the admission committees. For example, the undergraduate Grade Point Average (UGPA) minimum, if required, is predomi-

\footnotetext{
* Correspondence: Elizabeth Ann Doyle; Email: elizabeth.doyle@yale.edu; Address: Division of Primary Care, Yale School of Nursing, Yale University, USA. 
nately a 3.0 on a scale of $1-4$. Of the 21 programs, standardized tests [the Graduate Record Examination (GRE's)] are required by eight or $38 \%$ of the schools of nursing.

Accelerated direct entry programs for advanced practice are quite competitive since there are limited seats for potential candidates, given that so few programs exist. The limited availability of direct entry programs for non-nurse college graduates is juxtaposed again a current demand for APRNs. In the US, the necessity for Primary Care Providers (PCP) is outpacing the supply since medical students are primarily selecting specialty practice versus generalist preparation. In 2018 , of the 201,326 medical students who selected internal medicine as a specialty only $2.4 \%$ elected to practice in geriatric medicine and $.02 \%$ in adolescent medicine. ${ }^{[3]}$ It is projected that in 2025 , there will be a shortfall of physicians ranging from 34,600 to 88,000 with expected increasing needs by $2030^{[4]}$ and this need can be met by APRNs.

The Bureau of Labor ${ }^{[5]}$ estimates that opportunities for APRN will surge by 2024, partly due to the Affordable Care Act (ACA) passed in 2010, providing millions of Americans access to health insurance. ${ }^{[6-9]}$ These increasing numbers of patients will require more PCP' ${ }^{[8]}$ and APRNs are essential to bridging this gap. ${ }^{[10]}$ Because APRNs provide high-quality care and in many states are independent of physician oversight, it is crucial that their education and training prepare them as astute critical thinkers in the clinical decision-making process. ${ }^{[8,11]}$ Identifying those applicants who will succeed in rigorous programs of study, as well as those who will function as future competent, high quality health providers, is no simple task for admissions committee faculty.

From the student's perspective, the admissions process is the first step toward achieving their future goal as an APRN But faculty and administration also have a vital stake in the selection process as student's mirror the quality, mission and reputation of their institution. ${ }^{[12]}$ While admissions faculty must place importance on both an applicants' cognitive and non-cognitive attributes, it is imperative that cognitive measurements be both reliable and valid. ${ }^{[13-15]}$ Identifying attributes that best predict students' successful completion of their programs of study, as well as those who will provide safe, high-quality health care as future APRNs, is critical to the admissions selection process. ${ }^{[13]}$

\subsection{Admissions requirements and characteristics of ap- plicants}

Historically, requirements for graduate admission included the student's undergraduate transcript, UGPA, an applicant's essay or personal statement, letters of reference, standardized test scores such as the GRE (including verbal, quantitative, and writing scores), required prerequisite course work, and in some cases, personal interviews. ${ }^{[16]}$ None of these criteria should be viewed in isolation since "undergraduate transcripts reflect differential-grading standards practiced at individual institutions, personal statements are subjective and cannot determine the actual potential of the applicant and likewise, faculty letters of reference are subjective. The standardized, nationally normed examination is the most objective." (p. 271) $)^{[16]}$

\subsubsection{Standardized tests}

Specific to nursing graduate schools, both the GRE and the Miller Analogy Test (MAT) have been accepted criteria used for predicting success in the graduate school admission process $^{[17]}$ and studies in the 1980-1990's provide undeniable evidence that UGPA is predictive in many professional health care programs. ${ }^{[18-23]}$ But studies determining whether UGPA and/or the GRE successfully measure academic success in graduate health professional schools are widely varied and controversial $^{[24,25]}$ and while the UGPA may predict student success in one health professional program, it does not necessarily predict success in others. ${ }^{[24]}$

Criticism related to standardized testing points to its inability to measure a student's creativity or practical capability ${ }^{[26]}$ and whether students who obtain higher scores on standardized examinations, are simply better test takers, not necessarily guaranteeing academic success. ${ }^{[26]}$ Gibson, Leavitt, Lombard \& Morris ${ }^{[27]}$ found that those students who had no standardized testing data in their admission files had somewhat higher graduate school UGPA's than those who did take standardized tests. Others ${ }^{[28]}$ revealed measuring student's UGPA in their first three graduate level courses of a Master's in Public Administration degree, was more predictive of student success than were standardized test scores, thus a probationary acceptance period was offered to students with a final acceptance deemed upon grades in those initial three courses. Specific to graduate nursing school admissions, Katz, Chow, Motzer \& Woods ${ }^{[29]}$ found GRE scores did not strongly predict academic student success and potentially posed a barrier to application submission.

The GRE Board Research conducted their own study to determine if GRE scores were associated with success in graduate school and concluded that GREs were indeed a valid predictor of student success. ${ }^{[30]}$ However, the 2014 Educational Testing Service (ETS) which oversees the GRE advises that they do not measure qualities which may predict successful outcomes and cautions against the use of a "cutoff score". ${ }^{[31]}$ Conversely, establishing a threshold UGPA and GRE scores for Physician Assistant (PA) applicants signifi- 
cantly decreased students at risk for substandard academic performance. ${ }^{[32]}$

\subsubsection{Undergraduate grade point average (UGPA)}

On the surface, it would appear that UGPA is a strong predictor of graduate school success; however, Willingham ${ }^{[33]}$ cited two significant weaknesses. It generally has a narrow range from 3.0 to 4.0 "in many departmental candidate groups - and thus doesn't differentiate applicants very well. Also, the meaning of a B average varies considerably from one undergraduate college to another." (p. 274) ${ }^{[33]}$ While some studies link UGPA with graduate nursing school success, ${ }^{[3-39]}$ other studies associate both UGPA and GRE scores with successful program completion. ${ }^{[17,40]}$ Still others, link GREs rather than UGPA as predictors of success in nurse practitioner (NP) programs. ${ }^{[12,41]}$ Additionally, examining only science courses within the UGPA was predictive of academic success in $\mathrm{NP},{ }^{[42]}$ medical, ${ }^{[18]}$ and physiotherapy ${ }^{[43-45]}$ students. Rhodes and colleagues ${ }^{[17]}$ found that while the GRE correlated with both first-year and overall master's level GPA, the UGPA was a stronger predictor of success. It should be noted that most of the literature advocating for UGPA are dated and more recently the pervasive nature of grade inflation is suggesting that this variable does not carry the significance it once did. ${ }^{[46,47]}$ Specifically, Rojstaczer ${ }^{[47]}$ notes that the average UGPA change since 2000 at both public and private schools is 0.10 points per decade.

In 1985, Munro ${ }^{[48]}$ studied how admissions criteria predicted master's GPA (total, clinical and theoretical) at Yale School of Nursing's accelerated graduate program and found GREs (verbal and quantitative) as well as UGPA were significant predictors of theoretical and total master's GPA; however, they did not relate to clinical course grades. Specific to PA programs, while UGPA predicted the probability of attaining a satisfactory level of performance on the Physician Assistant National Certifying Examination (PANCE), both GRE verbal and quantitative scores were also found to positively

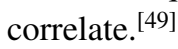

A graduate nursing program study revealed that UGPA was predictive of GRE scores and a UGPA of 3.28 predicted higher achievement in academic performance, thus admissions faculty at this program considered waiving the GRE mandate for those students who achieved this threshold. However, after contemplating grade inflation in undergraduate programs, this same graduate school opted to establish a UGPA threshold of 3.50 in order to waive the GRE requirement. ${ }^{[50]}$

\subsubsection{Diversity}

In recent years, health professional programs recognized that while the United States population has become increas- ingly diverse, the health professions have not reflected this change. ${ }^{[51,52]}$ In order to expand diversity in the health professions, institutions of higher learning must attract a competitive pool of students who not only meet admissions requirements but also successfully complete their programs of study. Students' who attended under resourced K-12 schools may lack the knowledge and tools necessary for admissions requirements, particularly in regard to standardized testing, placing them at risk for elimination from the health professional applicant pool. ${ }^{[53]}$ Sampson and Boyer ${ }^{[16]}$ conducted studies determining the utility of UGPA and GRE in minority students related to admissions requirements and subsequent completion of their health professional program and found that "... GRE-verbal score, age, major and undergraduate grade point averages are significantly associated with determining the first year average of minority students at a 'Research 1' university" (p. 277). Others found mandating GRE's for graduate nursing school admission posed barriers to some minority students who might otherwise have applied, ${ }^{[29]}$ and requiring GRE's in a PA program negatively impacted the number of minority students applying to their program. ${ }^{[53]}$ While the utility of GREs is debated particularly for underprivileged groups, an increase of students with diverse backgrounds has been on the rise in graduate schools nationally ${ }^{[54]}$ and thus the authors concluded that "the continued use of the GRE for admissions decisions has not blocked efforts toward equalizing representation in higher education" (p. 25). ${ }^{[54]}$ Similarly, $\mathrm{Cahn}^{[52]}$ determined that waiving GRE mandates for admission to professional health programs did not appear to automatically increase the representation or under representation of minority applicants and suggested that the most successful strategy should focus on effective minority recruitment.

\subsubsection{Age}

Age plays a factor regarding admissions requirements. Older students were found to be at a disadvantage related to success in graduate nursing programs. ${ }^{[35,55]}$ One theory is that older students have not been exposed to an academic environment for years and may find standardized examinations particularly difficult, ${ }^{[27]}$ which can increase test anxiety. ${ }^{[26]}$

\subsubsection{Gender}

When exploring GRE scores related to gender and success in graduate programs, the gap between men and women's scores has changed little over the past 30 years. Specifically, males score higher on quantitative and verbal GREs by $75-80$ points and 20-30 points respectively. ${ }^{[54]}$ Yet, it should be noted female enrollment in science, technology, engineering and math (STEM) graduate programs has increased considerably. ${ }^{[54]}$ 


\subsection{Objectives of this study}

There has been much debate in the literature regarding the validity of cognitive academic metrics and their association to academic success. Our retrospective study sought to determine which, if any of these metrics determined success in this first year of this graduate program. Success was defined as satisfactorily completing the first year of the program as opposed to those leaving due to substandard academic performance and performance on the first exam of seven different courses in the graduate plan of study. Specific aims were as follows:

- Aim 1. To determine if there are any differences in GRE and UGPA values based on gender, age, ethnicity, and race within this population.

- Aim 2. To determine if there were differences in UGPA and/or GRE scores among students who were successful in this program versus those who were not.

- Aim 3. To determine if GRE or UGPA scores are related to the first exam score on seven content-rich nursing courses, including Biomedical Foundations of Health and Disease, Human Anatomy, Introduction to Drug Therapy, Medical-Surgical Nursing, Maternal/Newborn Nursing, Pediatric Nursing, and Mental Health and Psychiatric Nursing.

- Aim 4. To determine if GRE or UGPA scores can predict performance on the first medical-surgical nursing exam. This course was responsible for $93.3 \%$ of failures out of this program.

\section{MethodS}

\subsection{Study design and setting}

This was a retrospective, descriptive study analyzing the admission metrics data and first year academic course performance in an accelerated master's entry program leading to advanced practice nursing within a university in the Northeast, United States. This school of nursing has PhD, DNP, and MSN programs. The MSN program includes the following specialties: family NP, adult and gerontology NP (acute and primary care), pediatric NP, psychiatric NP, women's health NP, and CNM. Among the 393 MSN students who enrolled in the program between 2016-2018, 333 or $85 \%$ were in the accelerated master's entry program, which requires completing a rigorous 11 months of study preparing students' to pass the National Council Licensure Examination for Registered Nurses (NCLEX-RN) and then advancing to their respective two year specialty program.

\subsection{Sample}

The sample consisted of 333 students who enrolled in the post-baccalaureate entry into professional nursing program over a three-year period (2016-2018). All students were included in the analysis if they enrolled in this specific program during this time period.

\subsection{Ethics}

This research was conducted at a graduate nursing program in a United States northeast university after obtaining an exempt status from the local institutional review board (The proposed research met the specific criteria for exemption status from the local institutional review board.). Each student was assigned a code number in the data base and once all data were entered, the codebook connecting student identifiers to their data was destroyed which prevented even the primary investigator from identifying any subject. Additionally, the data entry faculty member, a member of the admissions committee, is unaffiliated with the first-year courses for the non-nurse college graduate program. All data is presented in aggregate form only.

\subsection{Data collection}

All students who apply for the master's program are required to take the GREs, and submit their undergraduate and any other college transcripts (including their UGPA) to the admission committee for review. The first author obtained the quantitative metrics (GREs and UGPA) along with attrition rates and demographic data, including gender, age, race, and ethnicity, from the school's admission database. Examination scores were obtained from the faculty of record for the first exam in the following nursing courses in the master's entry nursing program: Biomedical Foundations of Health and Disease, Human Anatomy, Introduction to Drug Therapy, Medical-Surgical Nursing, Maternal/Newborn Nursing, Pediatric Nursing, and Mental Health and Psychiatric Nursing. Only the first exam score for each course was included, since students who scored poorly on the first exam in any course were offered 1:1 tutoring from faculty and teacher assistants to help them successfully perform on future examinations. Thus, subsequent exam scores were not analyzed since additional support could have skewed the data. All of this data was de-identified (each student was assigned a code number) and entered into an SPSS database for analyses.

\subsection{Data analysis}

IBM SPSS Version 24 was used for all data analyses. Statistical significance $(\alpha)$ was defined as a probability level of less than or equal to $5 \%(p<.05) . T$-tests and ANOVAs were used to determine if there were differences in mean GRE percentile scores and UGPA levels based on gender and race, and correlations were used to determine if age was related to these scores. $T$-tests were used to determine whether or not there was difference in GRE percentile scores and 
UGPA levels between those who were able to successfully complete the program vs. those who were not. Correlations were used to see if there were any significant relationships between GRE percentile scores and UGPA levels compared with the first exam score in seven different courses in the post-baccalaureate professional nursing program. To answer the fourth aim, multiple regression with a stepwise method was used to determine whether or not GRE percentile scores or UGPA levels on admission could predict later success on the first medical-surgical nursing exam, as this has been the course that students find most difficult.

\section{RESULTS}

\subsection{Subjects}

The data from 333 students entering the post-baccalaureate professional nursing program over a three year period were used for these analyses. The mean age was $27.9 \pm 4.4$ years, and $11.4 \%$ of the students were males. Their racial and ethnic backgrounds are described in Table 1.

Table 1. Race and ethnicity of sample

\begin{tabular}{ll}
\hline Characteristic & \# Students (\%) \\
\hline Race & $35(10.5)$ \\
Preferred Not to Answer & $226(67.9)$ \\
White & $7(5.1)$ \\
Black & $28(8.4)$ \\
Asian & $1(0.3)$ \\
Islander & $2(0.6)$ \\
Indian/White & $9(2.7)$ \\
Asian/White & $7(2.1)$ \\
Black/White & \\
Ethnicity & $26(7.8)$ \\
Preferred Not to Answer & $35(10.5)$ \\
Hispanic & $263(79)$ \\
Non-Hispanic & \\
\hline
\end{tabular}

\subsection{Differences in admission academic metrics based on demographics (Aim 1)}

\subsubsection{Age}

The student's age on enrollment was found to be weakly, negatively correlated with GRE quantitative percentiles ( $r$ $=-0.24, p<.001)$, and GRE writing scores $(r=-0.19, p<$ $.05)$. There was no relationship between age and GRE verbal percentiles nor the UGPA levels.

\subsubsection{Gender}

The differences in academic metrics related to gender are described in Table 2. There were no differences between males and females on both the GRE verbal and GRE quantitative percentiles. Female students performed better on the GRE writing test $(p<.05)$ and their UGPA levels were slightly higher (3.5 v.s. 3.4) and this difference was statistically significant $(p<.05)$.

Table 2. Academic metrics and gender

\begin{tabular}{llllll}
\hline $\begin{array}{l}\text { Academic } \\
\text { Metric }\end{array}$ & $\begin{array}{l}\text { Mean } \pm \text { SD } \\
\text { Male }\end{array}$ & $\begin{array}{l}\text { Mean } \pm \text { SD } \\
\text { Female }\end{array}$ & $t$ & df & $\boldsymbol{p}$ \\
\hline GRE verbal \% & $74.8 \pm 21.2$ & $74.4 \pm 19.3$ & 0.12 & 325 & .91 \\
GRE quant \% & $54.9 \pm 24.9$ & $51.7 \pm 20.1$ & 0.88 & 325 & .38 \\
GRE write \% & $60.1 \pm 26.5$ & $71.5 \pm 20.5$ & -3.02 & 325 & $.003^{*}$ \\
UGPA & $3.4 \pm 0.36$ & $3.5 \pm 0.28$ & -2.38 & 315 & $.018^{*}$ \\
\hline${ }^{*} p<.05$ & & & & &
\end{tabular}

\subsubsection{Race}

The differences in academic metrics related to race are described in Table 3. White students were compared with non-white students, and no differences were noted in both GRE verbal and quantitative percentiles. White students performed better on the GRE writing test $(p<.05)$ and had higher UGPA levels $(p<.05)$. A second analysis was completed separating the sample into three racial groups: White, Asian, and other, and there were no differences between the three groups with reference to GRE verbal and quantitative percentiles. However, there was a significant difference among the groups with reference to the GRE writing scores $(\mathrm{F}=3.4 \mathrm{df}=2, p<.05)$ and the UGPA levels $(\mathrm{F}=7.6$, $\mathrm{df}=2, p<.05)$. Bonferroni post-hoc tests revealed that white students had higher GRE writing scores than students who identified themselves as neither Asian nor white, and white students also had higher UGPA levels than both of the aforementioned groups. There was no difference in the GRE writing percentile nor the UGPA between Asians and those who identified themselves as white or non-white/or Asian.

Table 3. Academic metrics and race

\begin{tabular}{llllll}
\hline $\begin{array}{l}\text { Academic } \\
\text { Metric }\end{array}$ & $\begin{array}{l}\text { Mean } \pm \text { SD } \\
\text { White }\end{array}$ & $\begin{array}{l}\text { Mean } \pm \text { SD } \\
\text { Non-white }\end{array}$ & $\boldsymbol{t}$ & df & $\boldsymbol{p}$ \\
\hline GRE verbal \% & $76.8 \pm 17.5$ & $70.8 \pm 22.9$ & 1.94 & 85.1 & .55 \\
GRE quant \% & $53.8 \pm 19.3$ & $51.6 \pm 24.8$ & 0.65 & 86.0 & .52 \\
GRE write \% & $72.1 \pm 20.2$ & $65.0 \pm 24.9$ & 2.33 & 285 & $.021^{*}$ \\
UGPA & $3.6 \pm 0.27$ & $3.4 \pm 0.45$ & 3.35 & 79.9 & $.001^{*}$ \\
\hline${ }^{*} p<.005$ & & & & &
\end{tabular}

\subsubsection{Ethnicity}

There was no difference between those who identified themselves as Hispanic vs non-Hispanic on any of the academic metrics, including the GRE verbal $[t=-1.64(\mathrm{df}=39.8), p=$ $0.52]$, quantitative $[t=-2.0(\mathrm{df}=293), p=0.10]$, and writing percentiles $[t=-0.98(\mathrm{df}=293), p=.33]$, and the UGPA levels $[t=-0.45(\mathrm{df}=283), p=.65]$.

\subsection{Difference in admission metrics and success in pro- gram (Aim 2)}

Over the three years of study, 15 students ( $4.5 \%$ of students enrolled) have left the program because of academic failure 
during the first year of the master's entry into professional nursing program. This failure rate had increased from the 3 years prior (1.7\% failure rate). The primary reason for withdrawal for the last 3 cohorts who were studied was failure in the didactic medical-surgical nursing course $(93.3 \%)$ or pharmacology $(6.7 \%)$. Five students left the program in each year ( $4.5 \%$ of all of the students enrolled over three years). The admissions academic metrics were compared in the group that failed out of the program versus those that have remained as of the date of this report (see Table 4). While there were no differences in the mean UGPA $(p=.763)$, there was a statistically significant difference in all GRE measurements. Students who failed had significantly lower GRE quantitative percentile scores $[t=-2772$. $(\mathrm{df}=327), p=.006]$, verbal percentile scores $[t=-2.122(\mathrm{df}=14.65), p=.051]$ and significantly lower GRE writing percentile scores $[t=-3.912$ $(\mathrm{df}=327), p<.001]$.

\subsection{Admission academic metrics and performance in nursing courses (Aim 3)}

The academic metrics were then compared with the first exam score in seven content rich courses including: Biomedical Foundations of Health and Disease (mean score 86.2 \pm 10.0 ), Human Anatomy (mean score $92.5 \pm 5.2$ ), Introduction to Drug Therapy (mean score $88.0 \pm 11.6$ ), Medical-Surgical Nursing (mean score $84.4 \pm 9.0$ ), Maternal/Newborn Nursing (mean score $89.7 \pm 9.4$ ), Pediatric Nursing (mean score $90.0 \pm 5.3$ ), and Psychiatric Nursing (mean score $92.8 \pm$ 6.1). Data were not available for the most recent cohort for Maternal/Newborn Nursing, Pediatric Nursing and Psychiatric Nursing at the time of the writing of this manuscript, as these courses were not completed.

Table 4. Academic metrics and success in an accelerated nursing program

\begin{tabular}{lllll}
\hline Status & UGPA \pm SD & GRE Verbal $\% \pm$ SD & GRE Quant \% \pm SD & GRE Writing \% \pm SD \\
\hline Failed out of program & $3.52 \pm 0.26$ & $60.2 \pm 27.2$ & $37.8 \pm 27.7$ & $49.6 \pm 26.1$ \\
Matriculated in Program & $3.56 \pm 0.52$ & $75.3 \pm 18.9$ & $52.8 \pm 20.1$ & $71.3 \pm 20.8$ \\
\hline
\end{tabular}

The correlation matrix can be found in Table 5. The GRE verbal and quantitative percentile scores were correlated with the exam score in all of the courses except for Psychiatric Nursing. The GRE writing percentile score was correlated with the exam score on all of the courses except Biomedical Foundations and Psychiatric Nursing, although most of these correlations were weak. The UGPA levels were weakly correlated with all of the courses except for Biomedical Foundations (where there was no correlation). The strongest correlations were between the GRE quantitative scores and Pharmacology $(r=.484, p<.001)$, and Medical-Surgical Nursing ( $r=.458, p<.001)$, and both of these courses' tests were among the lower mean scores [Medical-Surgical Nursing (mean score $84.4 \pm 9.0$ ) and Pharmacology (mean score $88.0 \pm 11.6)]$. Interestingly, Maternal/Newborn Nursing which also had a lower mean test score $(85.9 \pm 7.6)$ was only weakly correlated with the GRE quantitative percentile ( $r=$ $.158, p<.05)$.

\subsection{Predicting performance on the medical surgical exam with admission academic metrics (Aim 4)}

Because students tend to struggle most in medical-surgical nursing, a multiple regression was used to help explain the variance seen in scores on the first medical surgical exam, based on the four admissions academic metrics. Neither UGPA scores, nor GRE writing scores were retained in the model. The final model, consisting of GRE quantitative per- centile scores and GRE verbal percentile scores explained $25.4 \%$ of the variance in the first medical-surgical exam scores $[\mathrm{F}=52.41(\mathrm{df}=2), p<.001]$, with the GRE quantitative scores having the most effect (GRE quantitative Beta $=$ .334 , and GRE verbal Beta = .240.).

\section{Discussion}

Entry into accelerated direct entry master's programs for advanced practice nursing is competitive and admission offices rely on a portfolio that includes both quantitative and qualitative measures. The two quantitative cognitive tools frequently used in graduate and doctoral admission selection process are the GREs and UGPA. Related to the admission metric of the GRE scores, this research reveals a statistically significant relationship between verbal, quantitative and writing GRE scores and successful advancement in the program of study. Additionally, the GRE verbal and quantitative scores were positively correlated with the first exam scores in six of seven content-rich nursing courses in first year of this program, where students are prepared as RNs. Interestingly, while the GRE continues to be viewed as a valuable metric for master's and doctoral work with predictive validity for success, ${ }^{[56]}$ many accelerated master's entry programs for advanced practice nursing have abandoned this metric in recent years. Currently only $38 \%$ of accelerated masters entry programs for advanced practice nursing have retained the GRE as a quantitative admission metric. 
Table 5. Correlation matrix for the academic metrics and nursing courses' first exam

\begin{tabular}{|c|c|c|c|c|c|c|c|c|c|c|c|c|}
\hline \multirow{2}{*}{ Course } & \multicolumn{3}{|c|}{ UGPA } & \multicolumn{3}{|c|}{ GRE Verbal \% } & \multicolumn{3}{|c|}{ GRE Quant \% } & \multicolumn{3}{|c|}{ GRE Writing \% } \\
\hline & $R$ & $p$ & $N$ & $R$ & $p$ & $N$ & $R$ & $p$ & $N$ & $R$ & $p$ & $N$ \\
\hline Anatomy & .147 & $.01^{*}$ & 305 & .238 & $\begin{array}{l}< \\
.001 * *\end{array}$ & 315 & .263 & $\begin{array}{l}< \\
.001 * *\end{array}$ & & .135 & $.02 *$ & 315 \\
\hline Pharmacology & .242 & $\begin{array}{l}< \\
.001^{* *}\end{array}$ & 307 & .291 & $\begin{array}{l}< \\
.001^{* *}\end{array}$ & 317 & .484 & $\begin{array}{l}< \\
.001^{* *}\end{array}$ & 317 & .270 & $\begin{array}{l}< \\
.001^{* *}\end{array}$ & 317 \\
\hline Med-Surg & .213 & $\begin{array}{l}< \\
.001^{* *}\end{array}$ & 313 & .418 & $\begin{array}{l}< \\
.001^{* *}\end{array}$ & 323 & .458 & $\begin{array}{l}< \\
.001^{* *}\end{array}$ & 323 & .299 & $\begin{array}{l}< \\
.001^{* *}\end{array}$ & 323 \\
\hline Maternal/Newb & .236 & $\begin{array}{l}< \\
.001^{* *}\end{array}$ & 247 & .187 & $.003^{*}$ & 254 & .158 & $.012 *$ & 254 & .120 & .057 & 254 \\
\hline Biomed & .039 & .494 & 307 & .212 & $\begin{array}{l}< \\
.001^{* *}\end{array}$ & 317 & .275 & $\begin{array}{l}< \\
.001^{* *}\end{array}$ & 317 & .106 & .060 & 317 \\
\hline Psychiatric & .249 & $.001 *$ & 187 & .112 & .124 & 191 & .096 & .188 & 191 & .122 & .092 & 191 \\
\hline Pediatric & .250 & $.001^{*}$ & 186 & .262 & $\begin{array}{l}< \\
.001^{* *}\end{array}$ & 190 & .207 & $.004 *$ & 190 & .201 & $.006^{*}$ & 190 \\
\hline
\end{tabular}

${ }^{* p}<.05 ; * * p<.001$

Katz and colleagues ${ }^{[29]}$ indicate that the GRE's present a barrier for minority populations applying to graduate nursing programs, and indeed, findings from this study reveal that master's entry students tend to be older, female and white. However, an increasing number of male students are electing to become APRNs, a finding noted nationally and historically in this population. ${ }^{[57,58]}$ Although a challenge for the nursing profession writ large is increasing the diversity of our workforce, it should be noted that a previous integrative review of master's entry programs for non-nurse college graduates leading to advanced practice revealed students were between $78 \%-100 \%$ white, ${ }^{[58]}$ whereas in this study the students were $67.9 \%$ white. Currently $30 \%$ of all baccalaureate, master's, doctoral, and doctor of nursing programs are students representing minority populations. ${ }^{[59]}$ Thus, while emphasis on increasing the number of nursing professionals from underrepresented minority groups must continue, some progress has been made. Furthermore, this study revealed no differences in both GRE verbal and quantitative percentiles when comparing white students to non-white students, indicating that there are potential applicants from underrepresented minority groups who meet the admission cognitive criteria of GREs. This data also supports the work of Cahn ${ }^{[52]}$ whose analysis of health professions graduate programs that eliminated the GREs did not automatically increase the diversity in their programs. Of note, there was a weak negative correlation between age and GRE quantitative scores, so admissions committee faculty members must factor this into their decisions about applicants.

The other quantitative cognitive metric traditionally used by admissions is the UGPA. This remains a required metric in all of the 21 accelerated master's entry programs, yet this

Published by Sciedu Press study failed to demonstrate a predictive relationship between this metric with successful progression through this program. It should be noted that since $2013,45 \%$ of all grades in United States community or four-year colleges have been an "A" with an average UGPA of 3.15. ${ }^{[47]}$ The work of Rojistaczer $^{[48]}$ and others ${ }^{[46,60,61]}$ suggests that a pattern of systematic grade inflation in the United States of 0.10 average increase in grades per decade or 0.2 points if a student graduated from a private college or university, has resulted in uncertainty regarding the predictive value of this metric. Additionally, in programs such as ours where there are vast differences in the academic majors of students, and a wide variety of both private and public institutions where students obtained their undergraduate degree, along with the historically high UGPAs of these students (ranges of 3.0 to 3.68 on a 4-point scale), ${ }^{[58]}$ concern over the use of UGPA as a single valid cognitive measure for academic success is at best subjective and at worst, a risk to the students, the faculty, university and public interest. Lastly, in this study, unlike the GRE quantitative and verbal scores, there were statistically significant differences in UPGA values with reference to gender and race, with female and white students having higher levels, suggesting that the UGPA may not be as an objective measure as the GRE quantitative and verbal scores.

\section{Limitations}

This study was limited to one accelerated master's entry program in a private university in the Northeast that prepares non-nurse college graduates for APRN practice thus in terms of number, geographic region, and type of institution, the generalizability of the study is limited. Additionally, $11 \%$ of the students in this study are male which is higher than the 
national rate of men in advanced practice nursing which is $1 \%$ for CNMs and $9 \%$ for NPs, whereas CRNAs are $44.5 \%$ male. ${ }^{[58,62]}$ Data was limited to admission metrics and scores on the first seven courses in this program of study as well as the ability to progress in the program. Other variables that the students may have suggested as essential for success or barriers to progression, were not ascertained in this study and would have added richness to our understanding. Finally, the variable of increased student enrollment in six years of $71 \%$ must be considered; that is 51 more students were admitted in 2018 than in 2013. Despite a concomitant increase in resources for the increased class size, there are unseen variables that also may have attributed to a $4.5 \%$ failure rate compared to $1.7 \%$ for previous classes.

\section{Conclusion}

With the shortage of PCP's projected for $2025^{[5]}$ it is critical for our nursing profession to continue to prepare APRNs to meet this demand. Given the efficiency of accelerated masters entry programs, it is not surprising that they are quite competitive among applicants, particularly because there are limited seats. Because these programs are intense and fast-paced, it is crucial that admissions committees select candidates who can meet this academic challenge. Additionally, the risk of failure must be addressed in terms of students' financial debt, time, and effort, as well as resource utilization and marketing efforts for the college or university. It is important to recognize that failure in master's entry program not only equates to an inability to become an APRN, but it also denies them the ability sit for the NCLEX; thus, these students will leave without the opportunity to become an RN. Admission committee faculty are therefore faced with selecting candidates with the least risk of failure in such a fast-paced academic program, based on data collected during the admissions process.
While the reliance on GRE scores for admissions has been criticized because of the potential barrier to minority students' applying to graduate programs, ${ }^{[29]}$ the data from this study suggests that the GRE quantitative and verbal scores predict later success in the most difficult nursing course, medical-surgical nursing. Of note, there were no differences in GRE scores among accepted students with reference to race, ethnicity, and gender. On the other hand, UGPA levels which are still heavily relied upon by many Master's entry programs for non-nurse college graduates, were not predictive of later success in medical-surgical nursing, and of concern, there were differences in the levels with reference to race and gender. Furthermore, there was no difference in the mean UGPA levels among students who failed out of the program compared with those who were successful, while there were differences seen with the GRE scores, with successful students performing better. Thus, this data suggests that GRE data may be more reliable data than the UGPA for admissions committee members to rely upon to help predict success in such academically difficult programs.

This data suggests that GRE scores remain an important objective variable for admissions committees to rely upon when making decisions about applicants, and therefore nursing programs may want to reconsider decisions to omit their use in evaluating candidates for their programs. However, they certainly are not the only indicator of success. Additional research is needed within the 21 colleges or universities who offer Advanced Practice Registered Nurse (APRN) programs for Master's entry programs for non-nurse college graduates to carefully determine what other objective admission criteria may predict academic success in these challenging, high paced programs.

\section{CONFLICTS OF INTEREST Disclosure}

The authors declare that there is no conflict of interest.

\section{REFERENCES}

[1] AACN: fact sheet: accelerated baccalaureate and master's degrees in nursing [Internet]. Washington, DC: American Association of Colleges of Nursing; c2019 [cited 2019 Jul 3]. Available from: https://www.aacnnursing.org/Nursing-Educa tion-Programs/Accelerated-Programs

[2] Martinez PR. The academic impact of prerequisite coursework for second degree students in an accelerated graduate entry prespecialty in nursing program [dissertation]. [New Haven (CT)]: Southern Connecticut State University; 2015.

[3] ABIM: number of candidates certified [Internet]. Philadelphia: American Board of Internal Medicine c2019 [cited 2019 July 3]. Available from: https://www.abim.org/about/statistics-dat a/candidates-certified
[4] IHS Market. 2017 update: The complexities of physician supply and demand: Projections from 2015 to 2030: final report. Washington (DC): Association of American Medical Colleges; 2017 Feb. 54p.

[5] United States Department of Labor: occupational outlook handbook, nurse anesthetists, nurse midwives, and nurse practitioners [Internet]. Washington: United States Department of Labor c2019 [cited 2019 July 31]. Available from: https://www.bls.gov/ooh/healthcare/nurse-anestheti sts-nurse-midwives-and-nurse-practitoners.htm

[6] Blumenthal D, Collins SR. Health care coverage under the Affordable Care Act-a progress report. N Engl J Med. 2014 Jul 17; 371(3): 275281. PMid:24988300 https://doi.org/10.1056/NEJMhpr 140 5667

[7] Carthon JMB, Barnes H, Sarik DA. Federal policies influence access 
to primary care and nurse practitioner workforce. J of Nurse Practitioners. 2015; 11(5): 526-530. PMid:26457073 https://doi.org/ $10.1016 / j$.nurpra. 2015.01.028

[8] Iglehart JK. Expanding the role of advanced nurse practitionersrisks and rewards. New Eng J Med. 2013; 368(20): 1935-41. PMid:23675663 https://doi.org/10.1056/NEJMhpr1301084

[9] Grossman EG, Sterkx CA, Blount EC, et al. Compilation of patient protection and the affordable care act. Washington (DC): Office of the Legislative Counsel for the use of the United States House of Representatives; 2010 Jun. Public Law: 111-48.

[10] ANA: advanced practice registered nurse [Internet]. Washington: American Nurses Association; c2019 [cited 2019 Jul 31]. Available from https://www. nursingworld.org/practice-polic y/workforce/what-is-nursing/aprn/

[11] Newhouse RP, Stanik-Hutt J, White KM, et al. Advanced practice nurse outcomes 1990-2008: a systematic review. Nurs Econ. 2011 Sep-Oct; 29(5): 230-50; quiz 251.

[12] Hagedorn LS, Nora A. Rethinking admissions criteria in graduate and professional programs. New Directions Institutional Res. 1996 Winter; 1996(92): 31-44. https://doi.org/10.1002/ir.37019 969205

[13] Salvatori P. Reliability and validity of admissions tools used to select students for the health professions. Adv Health Sci Educ Theory Pract. 2001; 6(2): 159-175. https://doi.org/10.1023/A: 1011489618208

[14] Agho AO, Mosley BW, Smith-Paul B. Use of the interview in selecting students for occupational therapy programs. Am J Occup Ther. 1998 Jul-Aug; 52(7): 592-594. PMid:9693706 https: //doi.org/10.5014/ajot.52.7.592

[15] Scott AH, Chase LM, Lefkowitz R, et al. A national survey of admissions criteria and processes in selected allied health professions. J Allied Health. 1995; 24(2): 95-107.

[16] Sampson C, Boyer PG. GRE scores as predictors of minority students' success in graduate study: an argument for change. College Student J. 2001; 35(2): 271-279.

[17] Rhodes ML, Bullough B, Fulton J. The Graduate Record Examination as an admission requirement for the graduate nursing program. $\mathrm{J}$ Prof Nurs. 1994 Sep-Oct; 10(5): 289-296. https://doi.org/10 .1016/8755-7223(94) 90054-X

[18] Cariaga-Lo LD, Enarson CE, Crandall SJ, et al. Cognitive and noncognitive predictors of academic difficulty and attrition. Acad Med. 1997 Oct; 72(10 Suppl 1): S69-71. PMid:9347744 https: //doi.org/10.1097/00001888-199710000-00047

[19] Balogun JA. Predictive validity of the Allied Health Professions Admissions Test. Physiotherapy Canada. 1987 Jan; 39(1): 39-42.

[20] Hansen MJ, Pozehl BJ. The effectiveness of admission criteria in predicting achievement in a master's degree program in nursing. J Nurs Educ. 1995 Dec; 34(9): 433-437.

[21] Holt TBO, Dunlevy CL. The use of pre-admission criteria to predict academic success in a 4-year respiratory care curriculum. Resp Care. 1992; 37(5): 439-443.

[22] Kirchner GL, Holm MB. Prediction of academic and clinical performance of occupational therapy students in an entry-level master's program. Am J Occup Ther. 1997 Oct; 51(9): 775-779. PMid:9311434 https://doi.org/10.5014/ajot.51.9.775

[23] Kulatunga-Moruzi C. Toward valid selection criteria for academic and professional excellence in medicine [thesis]. [Hamilton, Ontario]: McMaster University; 1998.

[24] Wilcox RE, Lawson KA. Predicting performance in health professions education programs from admissions information - Comparisons of other health professions with pharmacy. Curr Pharm Teach
Learn. 2018; 10(4): 529-541. PMid:29793718 https ://doi.org/ $10.1016 /$ j.cptl. 2017.12 .004

[25] Freely TH, Williams V, Wise T. Testing the predictive validity of the GRE exam on communication graduate student success: a case study at University at Buffalo. Communication Quart. 2005; 53(2): 229-245. https://doi.org/10.1080/01463370500090209

[26] Fedynich L. The grand questions: do entrance examinations determine graduate student academic success? Res Higher Educ J. 2017 Nov; 33: 1-8.

[27] Gibson PA, Leavitt WM, Lombard JR, et al. Acknowledging the professional in a professional degree program: waiving the standardized exam for in-service applicants to a MPA program. College Student J. 2007 Dec; 41(4): 872-885.

[28] Thompson L, Kobrak P. Predicting the success of students in an MPA program. Teaching Polit Sci: J Soc Sci. 1983 Summer; 10(4): 182188. https://doi.org/10.1080/00922013.1983.9942613

[29] Katz JR, Chow C, Motzer SA, et al. The graduate record examination: help or hindrance in nursing graduate school admissions. J Prof Nurs. 2009 Nov-Dec; 25(6): 369-372. PMid:19942205 https://doi.org/10.1016/j.profnurs . 2009.04.002

[30] Young JW, Klieger D, Bochenek J, et al. The validity of scores from the GRE revised General Test for forecasting performance in business schools: phase one. Princeton (NJ): Educational Testing Service; 2014. GRE Board Research Report No. 14-01; ETS Research Report No. RR-14-17).

[31] Moneta-Koehler L, Brown AM, Petrie KA, et al. The limitations of the GRE in predicting success in biomedical graduate school. PLoS ONE. 2017; 12(1): e0166742. PMid:28076356 https ://doi .org/ 10.1371/journal. pone. 0166742

[32] Luce D. Screening applicants for risk of poor academic performance: a novel scoring system using preadmission grade point averages and graduate record examination scores. J Physician Assist Educ. 2011; 22(3): 15-22. https://doi.org/10.1097/01367895-2011220 30-00002

[33] Willingham WW. Predicting Success in Graduate Education: Improved selection procedures are likely to come from better definitions of "success". Science. 1974 Jan 25; 183(4122): 273-278. PMid:17821072 https://doi.org/10.1126/science.183.41 22.273

[34] Auerhahn C. Predictors of success in master's level nurse practitioner programs [Dissertation]. [New York (NY)]: Columbia University; 1996.

[35] Ortega KH, Burns SM, Hussey LC, et al. Predicting success in nurse anesthesia programs: an evidence-based review of admission criteria. AANA J. 2013 Jun; 81(3): 183-189.

[36] Suhayda R, Hicks F, Fogg L. A decision algorithm for admitting students to advanced practice programs in nursing. J Prof Nurs. 2008 Sep-Oct; 24(5): 281-284. PMid:18804081 https ://doi .org/10 $.1016 / j$. profnurs .2007 .10 .002

[37] Patzer B, Lazzara EH, Keebler JR, et al. Predictors of Nursing Graduate School Success. Nurs Educ Perspect. 2017 Sep/Oct; 38(5): 272274. PMid:28614099 https://doi.org/10.1097/01. NEP.000 0000000000172

[38] Brown LB. An exploratory study of predictors of academic success in a graduate nursing program [thesis]. [Allendale (MI)]: Grand Valley State University; 2011. 658.

[39] Fuller KM. Identification of pre-admission criteria predictive of success in graduate nurse anesthesiology programs. [dissertation]. [Albany (NY)]: State University of New York: Albany; 2015.

[40] Jewell DV, Riddle DL. A method for predicting a student's risk for academic probation in a professional program in allied health. $\mathbf{J}$ Allied Health. 2005; 34(1): 17-23. 
[41] Richard-Eaglin A. Predicting student success in nurse practitioner programs. J Am Assoc Nurse Pract. 2017 Oct; 29(10): 600-605. PMid:28805350 https ://doi.org/10.1002/2327-6924.1250 2

[42] Foti I, DeYoung S. Predicting success on the National Council Licensure Examination-Registered Nurse: another piece of the puzzle. J Prof Nurs. 1991 Mar-Apr; 7(2): 99-104. https://doi.org/10.1 016/8755-7223(91) 90093-Z

[43] Baker J, Douphrate D, Riley D. The use of the Revised PSB-Health Occupations Aptitude Examination as a predictor of success in physical therapy students. J Phys Ther Educ. 1996 Oct; 10(2): 63-67. https://doi.org/10.1097/00001416-199607000-00003

[44] Roehrig S. Prediction of student problems in a baccalaureate physical therapy program. J Phys Ther Educ. 1990 Jan; 4(1): 26-30. https://doi.org/10.1097/00001416-199001000-00007

[45] Templeton MS, Burcham A, Franck L. Predictive study of physical therapy admission variables. J Allied Health. 1994; 23(2): 79-87.

[46] Kostal JW, Kuncel NR, Sackett PR. Grade inflation marches on Grade increases from the 1990s to 2000s. Educ Measurement: Issues Pract. 2016 Spring; 3(1): 11-20. https : //doi .org/10.1111/em ip. 12077

[47] Rojistaczer S. Grade Inflation of American Colleges and Universities, 2002-2013. 2016.

[48] Munro BH. Predicting success in graduate clinical specialty programs. Nurs Res. 1985 Jan-Feb; 34(1): 54-57. https ://doi .org/ 10.1097/00006199-198501000-00011

[49] Higgins R, Moser S, Dereczyk A, et al. Admission variables as predictors of PANCE scores in physician assistant programs: a comparison study across universities. J Physician Assist Educ. 2010; 21(1): 10-17. https://doi.org/10.1097/01367895-201021010-00002

[50] Newton SE, Moore G. Undergraduate grade point average and graduate record examination scores: the experience of one graduate nursing program. Nurs Educ Perspect. 2007 Nov-Dec; 28(6): 327-331.

[51] Valentine P, Wynn J, McLean D. Improving diversity in the health professions. N C Med J. 2016 Mar-Apr; 77(2): 137-140. PMid:26961841 https://doi.org/10.18043/ncm.77.2.137

[52] Cahn PS. Do health professions graduate programs increase diversity by not requiring the graduate record examination for admission. $\mathbf{J}$ Allied Health. 2015; 44(1): 51-56.
[53] Wolf C. The effect of the graduate record examination on minority applications: experience at New York Institute of Technology. J Allied Health. 2014; 43(4): e65-7.

[54] Bleske-Rechek A, Browne K. Trends in GRE scores and graduate enrollments by gender and ethnicity. Intelligence. 2014 Sept-Oct; 56: 25-32. https ://doi.org/10.1016/j.intell.2014.05.005

[55] Kuncel NR, Wee S, Serafin L, et al. The validity of the Graduate Record Examination for master's and doctoral programs: a metaanalytic investigation. Educ Psych Measurement. 2010 Apr; 70(10): 340-352. https : //doi.org/10.1177/0013164409344508

[56] Zaglaniczny KL. Factors which predict performance on the National Certification Examination for Nurse Anesthetists. AANA J. 1992 Dec; 60(6): 533-540.

[57] Sipe TA, Fullerton JT, Schuiling KD. Demographic profiles of certified nurse-midwives, certified registered nurse anesthetists, and nurse practitioners: reflections on implications for uniform education and regulation. J Prof Nurs. 2009 May-Jun; 25(3): 178-185. PMid:19450789 https ://doi.org/10.1016/j.profnurs . 200 9.01 .002

[58] Pellico LH, Terrill E, White P, et al. Integrative review of graduate entry programs in nursing. J Nurs Educ. 2012 Jan; 51(1): 29-37. PMid:22132716 https://doi.org/10.3928/01484834-20111 130-01

[59] Campaign for Action: increasing diversity in nursing [Internet]. Washington: Center to Champion Nursing in America, c 2019 [cited 2019 Jul 30]. Available from: https : //campaignforaction. or g/issue/increasing-diversity-in-nursing/

[60] Rojistaczer S, Healy C. Grading in American colleges and universities. Teachers College Record. 2010 Jan [cited 2019 Jul 30]. Available from: http://www.tcrecord.org/PrintContent.as p?brContent ID $=15928$

[61] Rojistaczer S, Healy C. Where A is ordinary: the evolution of American college and university grading, 1940-2009. Teachers College Record. 2012 July; 114(7): 1-23.

[62] Smiley RA, Lauer P, Bienemy C, et al. The 2017 national nursing workforce survey. J Nurs Regulation. 2018 Oct; 9(Suppl. 3): S1-S88. https://doi .org/10.1016/S2155-8256(18)30131-5 